\title{
Post Model Correction in Risk Analysis and Management
}

\author{
G.-J. Siouris, D. Skilogianni, A. Karagrigoriou* \\ Lab of Statistics and Data Analysis \\ Department of Statistics and Actuarial-Financial Mathematics \\ University of the Aegean, Greece \\ *Corresponding author: alex.karagrigoriou@ aegean.gr
}

(Received January 19, 2019; Accepted February 21, 2019)

\begin{abstract}
This work focuses on Value at Risk (VaR) and Expected Shortfall (ES) in conjunction with the so called, low price effect. In order to improve forecasts of risk measures like VaR or ES when low price effect is present, we propose the low price correction which does not involve additional parameters and instead of returns it relies on asset prices. The forecasting ability of the proposed methodology is measured by appropriately adjusted popular evaluation measures, like MSE and MAPE as well as by backtesting methods. For illustrative and comparative purposes a real example from the Athens Stock Exchange as well as a number of penny stocks from Nasdaq, NYSE and NYSE MKT are fully examined. The proposed technique is always applicable, but its superiority and effectiveness is evident in extreme economic scenarios and severe stock collapses. The proposed methodology that pays attention not only to the asset return but also to the asset price, provides sufficient evidence that prices could contain important information which could if taken under consideration, results in improved forecasts of risk estimation.
\end{abstract}

Keywords- EWMA, ARCH, GARCH, APARCH, FIGARCH, Expected shortfall, VaR, PVaR, Violation ratios; Normalised shortfall, EPS, Leverage effect, Low price effect, Low price correction, Backtesting.

\section{Introduction}

The quantification of risk is an important issue in finance that becomes even more important during periods of financial crises. Risk measures have been proposed and used, over the years, to evaluate the overall risk exposure for the purpose of financial supervision including internal control and banking supervision. Value at Risk is the most popular of such measures primarily due to its simplicity. Furthermore, $\mathrm{VaR}$ is easily validated and backtested by simply comparing predicted and actual values. On the other hand, VaR is not a formal risk measure since it fails to fulfill the axiom of sub-additivity according to which portfolio diversification leads to risk reduction. An additional drawback of $\mathrm{VaR}$ is its inability to capture tail risk. The heavy tail property refers to instances with large positive or negative returns unlikely to be observed in bell-shaped symmetric returns. Simply speaking, measures like VaR do not provide information about the magnitude of the loss beyond a threshold level. Fat tails is one of the financial concepts that appear frequently and is considered as one of the sources of inadequate and often inaccurate estimation of the total risk exposure (Demírgüç-Kunt and Levine, 1996; Cont, 2001). The introduction of the Expected Shortfall as a new risk measure that possesses the sub-additivity property and measures the loss in the tail, came naturally as a response to the criticism of VaR (Artzner et.al., 1999; Acerbi and Tasche, 2002).

The estimation of volatility is the main financial characteristic associated with risk analysis and management. In order to forecast simultaneously returns and volatility, different models have been developed over the years which include, among others Moving average models (MA), Exponentially weighted moving average models (EWMA), Autoregressive conditional heteroskedasticity models (ARCH), Generalized ARCH (GARCH) models and their extensions, 
International Journal of Mathematical, Engineering and Management Sciences

Vol. 4, No. 3, 542-566, 2019

https://dx.doi.org/10.33889/IJMEMS.2019.4.3-044

Asymmetric and Power GARCH models (APARCH) and Fractionally Integrated GARCH models (FIGARCH) (Engle, 1982; Bollersley, 1986; Robinson, 1991; Baillie et. al., 1996; Poon and Granger, 2003; Taylor, 2004; Belkhouja and Boutahary, 2011). Each of these models provide answers to specific aspects of managing and controlling risk exposure.

A financial characteristic that affects the evaluation of both volatility and risk is the leverage effect (Black, 1976; Christie, 1982), which emerges from the negative correlation often observed between stock returns and volatility. Due to this effect, asset volatility increases with negative financial news and decreases with positive ones, while returns behave in exactly the opposite way. Furthermore, another characteristic that inevitably affects volatility but is frequently overlooked, is the so called low price effect (lpe) (Fritzemeier, 1936) according to which primarily in periods of economic instability, low price stocks fluctuate nervously resulting in increased volatility.

Our motivation for the present work comes from recent events in the Greek Stock Market, where the financial crisis resulted in the collapse of the banks' stock prices and a dramatic change in volatility. Consequently, this type of events fails to accurately predict the risk of stocks. Such inaccurate predictions also occur in penny stocks (which represent a great amount of stocks in any given market) which are stocks that are usually underrepresented in financial news, they are underreported and usually less regulated since they are associated with small companies, in their start. As a result, the risk associated with these stocks, is usually greater. The present work attempts to provide a mathematical reasoning behind the increase volatility of low priced stocks except of the aforementioned issues. This will be achieved by utilising the discrete nature of returns, that emerges when prices are low enough. Also, in order to illustrate the results of our proposed methodology we provide appropriate adjustments of well-known evaluation measures. This adjustment by itself is important, since it provides a way to evaluate percentile estimations such as VaR estimations, which was not previously possible. Last but not least, we apply our methodology to a warrant. This special case of derivatives is an excellent example of the power and significance of the proposed methodology, as well as its usefulness in derivatives, in general. The implementation of the proposed correction leads to extremely improved forecasting ability as it is shown in the application Section.

The internal complexity of the financial system together with the presence of at least some of the characteristics like the leverage effect, the heavy-tail property or the low price effect make the search for an ideal model extremely difficult. Furthermore, in the presence of extreme and abrupt economic events, econometric models become unreliable and the estimation of risk exposure is both unstable and inaccurate with serious consequences not only on the model's forecasting ability but also on asset allocation, portfolio management, risk management, economic capital and financial stability. Any attempt to increase the reliability of the model identification procedure for volatility estimation results unavoidably in even more complex models which still will be unable to identify and fully capture the complete set of components governing global economy.

In this work we focus on the most popular risk measures and propose a low price correction (lpc) for improving their forecasts, when the low price effect is present. The pioneering of the proposed correction is that it does not require any additional parameters and takes into account the asset price. The proposed correction is associated with the rationalization of the estimated asset returns since it is the next integer multiplier of the minimum possible return. Our methodology focuses on Percentage Value at Risk (PVaR) and Expected Percentage Shortfall (EPS) in order to complement and extend previous work by Siouris and Karagrigoriou (2017). Note that we prefer to deal with 
International Journal of Mathematical, Engineering and Management Sciences

Vol. 4, No. 3, 542-566, 2019

https://dx.doi.org/10.33889/IJMEMS.2019.4.3-044

the percentage value at risk for comparative reasons between stocks of the same portfolio with different allocation. In order to judge the forecasting quality of the proposed methodology, we rely on backtesting methods, such as the violation ratio (VR) for Value at Risk, and normalised shortfall (NS) for Expected Shortfall, as well as appropriate adjustments of a number of popular evaluation measures, like the Mean Square Error (MSE), the Mean Absolute Error (MAE), and the Mean Absolute Percent Error (MAPE). As we will show later on, the standard evaluation measures fail to quantify the forecasting ability of each model, since $\mathrm{VaR}$ is a percentile estimation. The decrease in the values of the proposed adjusted measures, will show the improved forecasting quality of the proposed methodology.

The paper is organized as follows. The low price effect together with the proposed methodology for improved volatility estimation is presented in Section 2. The low price correction for the Percentage Value at Risk (PVaR) and the Expected Percentage Shortfall (EPS) can be found in Sections 2.1 and 2.2 respectively. Evaluation techniques and backtesting are discussed in Section 2.3. For the implementation, in Section 3, we use the warrants of National Bank of Greece stock (of Athens Stock Exchange) which exhibits violent changes in its price, together with volatility structural changes due to the abnormal economic environment under which it operates, as well as a number of penny stocks from Nasdaq, NYSE and NYSE MKT, on which low price effect is not only present but also extremely intense.

\section{The Low Price Effect and Correction}

Stock exchange markets operate with certain accuracy. Although in most European markets the accuracy is fixed and equal to 0.1 cents (0.001 euros), U.S. markets operate under different accuracies depending on the stock value. In case of NYSE equities rule 7.6 reads:" The minimum price variation ("MPV") for quoting and entry of orders in securities traded on the NYSE Arca Marketplace is USD 0.01, with the exception of securities that are priced less than USD 1.00 for which the MPV for quoting and entry of orders is USD 0.0001". For NASDAQ equities rule 4701 (k) reads". The term" minimum price increment" means USD 0.01 in the case of a System Security priced at USD 1 or more per share, and USD 0.0001 in the case of a System Security priced at less than USD 1 per share." Although the accuracy is readjusted for extremely low price assets the associated fluctuation is considerable and the corresponding volatility is automatically increased. The phenomenon is magnified considerably in periods of extreme economic conditions (economic collapses, bankruptcies, depressions, etc.) and as a result typical market accuracy fails to handle smoothly assets of extremely low price. Such extreme events have occurred during the last decade across the globe, starting with 2007 in the US market and split over to the EU markets. Indeed, since all possible (logarithmic) returns on a specific day are integer multiples of the minimum possible return, the stock movement will fluctuate nervously so that violations will occur more frequently and forecasts will turn out to be irrational in the sense that such returns cannot be materialized. The resulting volatility increase is quite often overlooked primarily due to the fact that one takes into consideration the returns, neglecting entirely the asset prices. In this section we discuss the low price effect and propose a low price correction for both Percentage Value at Risk and Expected Percentage Shortfall.

In order to accommodate different accuracies, we introduce below a broad definition of the minimum possible return.

Definition 1. Let $p_{t}$ be the asset value at time $t$ and $c\left(p_{t}\right)$ be the minimum price variation (market accuracy) associated with the value of the asset at time $t$. Then the minimum possible return of an 
International Journal of Mathematical, Engineering and Management Sciences

Vol. 4, No. 3, 542-566, 2019

https://dx.doi.org/10.33889/IJMEMS.2019.4.3-044

asset at time $t$ denoted by $m p r_{t}$ is the logarithmic return that the asset will produce if its value changes by $c\left(p_{t}\right)$ and is given by:

$$
m p r_{t}=\log \left(\frac{p_{t}+c\left(p_{t}\right)}{p_{t}}\right)
$$

Note that $m p r_{t}$ is the same for both upward and downward movements due to symmetry of logarithmic returns. For the special case, where a market has a constant accuracy, say $c$, irrespectively of the stock price, the above definition can be simplified to $m p r_{t}=\log \left(\left(p_{t}+c\right) / p_{t}\right)$ (see Siouris and Karagrigoriou, 2017).

Definition 2. Low price effect (lpe) is the inevitable increase of variance in stocks with low prices due to the existence of a minimum possible return.

Considering that the probability mass will be concentrated to the next integer multiplier of the minimum possible return, we have that the volatility, provided that it exists, is increased to

$$
\sum_{k=-\infty}^{+\infty} \sup _{R_{t} \in[k \cdot m p r,(k+1) \cdot m p r]}\left(R_{t}-\mu\right)^{2} \int_{k \cdot m p r}^{(k+1) \cdot m p r} f\left(R_{t}\right) d R_{t}
$$

where $R_{t}$ the return at time $t$ and $f(\cdot)$ and $\mu$ the density and the mean of returns.

The above definition although of the same philosophy is slightly different from the original concept introduced by Fritzemeier (1936) who observed that low-priced stocks were characterized by higher returns and higher volatility. Such high volatility whenever observed, was attributed to increase returns although the discrete nature is the one to be blamed for both increased returns and volatility. According to Clendenin (1951) the lpe is attributed to the low quality of stocks perceived by investors. Most results on lpe (Christie, 1982; Desai and Jain, 1997; Hwang and Lu, 2008; Jana et.al., 2018; Wang and Alexander, 2019) deal with the US market although in the literature one can find some examples on other markets. Such markets include the Warsaw Stock Exchange (Zaremba and Zmudziński, 2014), the Johannesburg Stock Exchange (Gilbertson et. al., 1982; Waelkens and Ward, 1997) and the Athens Stock Exchange (Siouris and Karagrigoriou, 2017). A general conclusion that can be derived from these results is that the decision on the cut-off point for a lowprice share may be a subjective one, but the researcher is free to consider and explore various cutoff points in search for an idealistic threshold, if it exists. For both practical and theoretical purposes any value can be adapted provided that above this threshold, the market is assumed or believed to operate not as efficiently as it should have been. For the purposes of the current work, the value $\Theta=0.001$ or $0.1 \%$ is arbitrarily chosen to play the role of the pre-assigned threshold or cut-off point. The investigation of the discrete nature returns and from which point onward is crucial to our estimations as well as the behavior of lpc for various levels of threshold, is left for future work.

Definition 3. Low price effect area is the range of prices for which the $m p r$ is greater than a prespecified threshold $\Theta$.

It must be noted that the minimum possible return is a result of the combination of a low price with a minimum possible variation for the stock. As a result, a minimum possible return occurs. 
International Journal of Mathematical, Engineering and Management Sciences

Vol. 4, No. 3, 542-566, 2019

https://dx.doi.org/10.33889/IJMEMS.2019.4.3-044

Example 1. The low price effect area can be easily defined by applying Definition 1 for specific values of the accuracy and the threshold.

(a) For a stock exchange market which operates under accuracy $c=c\left(p_{t}\right)=0.001$, and a predefined threshold $\Theta=0.001$, we get $p_{t}=0.999001$. Thus, the low price effect area is given by $p_{t} \leq 0.999$ and an appropriate technique to resolve the low price effect should be implemented.

(b) Equivalently, for stock exchange markets like NYSE and NASDAQ, we would have for the same threshold $\Theta=0.001$, two different cases:

- $\quad$ for $p_{t} \geq 1$ implying that $p_{t}=9.995002$ and

- $\quad$ for $p_{t}<1$ implying that $p_{t}=0.09995002$.

Thus, for $1 \leq p_{t} \leq 10$ and for $p_{t} \leq 0.100$ the low price effect is present and proper actions should be taken to minimize it. While in the range of 1 to 10 dollars numerous real life examples can be found, the same is not true for prices under 0.1 dollars, in which case, the stock has already been halted from the stock market, and hence, lpe makes only theoretical sense and becomes a theoretical concept.

(c) For derivative markets, while the accuracy is greater, the behaviour of derivatives is even more extreme. In these markets, derivatives quite often are negotiated to extremely low prices that exceed by far the aforementioned threshold $\Theta$ of $0.1 \%$.

For the resulting low price effect area, the models considered should be appropriately adapted. This adaptation is done through the so called low price correction of both the estimation of percentage value at risk denoted by PVaR and the expected percentage shortfall (EPS) to be introduced respectively in the following two subsections.

\subsection{Percentage Value at Risk (PVaR) and Low Price Correction}

The Percentage Value at Risk which is a risk measure for estimating the possible percentage losses from trading assets, within a set time period, is defined as follows:

Definition 4 (a) Percentage Value at Risk $p(\operatorname{PVaR}(p))$ is the 100pth percentile of the distribution of returns.

(b) Percentage Value at Risk $p$ at time $t\left(\operatorname{PVaR}_{t}(p)\right)$ is the abovementioned risk measure at time $t$.

The probability of a $\operatorname{PVaR}_{t}(p)$ violation is given by

$$
p=\operatorname{Pr}\left[R_{t} \leq-P V a R_{t}(p)\right]=\int_{-\infty}^{-P V a R_{t}(p)} f(x) d x
$$

where $R_{t}$ is the random variable of returns at time $t$, and $f(\cdot)$ is the probability density function of returns. 
International Journal of Mathematical, Engineering and Management Sciences

Vol. 4, No. 3, 542-566, 2019

https://dx.doi.org/10.33889/IJMEMS.2019.4.3-044

Since we defined $\operatorname{PVaR}_{t}(p)$ based on the return distribution, no additional specification of the equation is needed on whether simple or logarithmic returns are available. Usually, the computation is done over standardized returns. Thus,

$$
\begin{aligned}
p & =\operatorname{Pr}\left(R_{t} \leq-\operatorname{PVaR}_{t}(p)\right) \\
& =\operatorname{Pr}\left(\frac{R_{t}}{\sigma} \leq-\frac{\operatorname{PVaR}_{t}(p)}{\sigma}\right)
\end{aligned}
$$

where the distribution of standardized returns with standard deviation $\sigma,\left(R_{t} / \sigma\right)$, is denoted by $F(\cdot)$. Hence, the PVaR of an asset takes the form

$$
\operatorname{PVaR}_{t}(p)=-\sigma F^{-1}(p)
$$

where $F^{-1}(p)$ is the $100 p^{\text {th }}$ percentile of the assumed distribution.

Note that for the evaluation of $\mathrm{PVaR}_{t}(\mathrm{p})$, one may consider any econometric model and then apply an estimation technique for the model parameters. For the distribution $F$ we consider, in this work, the normal, the Student-t and the skewed Student-t distribution (Lambert and Laurent, 2001). In case where the standardized returns are generated from a Student- $t$ distribution with $v$ degrees of freedom, variance is equal to $v /(v-2)$, hence, it is never equal to one. If that sample variance is used in the calculation of $P V a R$, the $P V a R$ would be overestimated. Volatility effectively shows up twice, both in $F^{-1}(p)$ and in the estimation $\hat{\sigma}$ of $\sigma$ which is obtained by numerical maximization of the log-likelihood. Hence, we need to scale volatility by

$$
\sigma^{2} \equiv \frac{v}{v-2} \tilde{\sigma}^{2}
$$

where $\tilde{\sigma}_{2}$ is the variance in excess of that implied by the standard Student- $t$.

We close this section with the definition of the low price correction for the Percentage Value at Risk. A $\operatorname{PVaR}_{t}(p)$ estimate can take any real value not necessarily equal to integer multiples of $m p r_{t}$. Under the low price effect, stock movements become inevitably more nervous and any model used, would produce forecasts that are irrational in the sense that stocks cannot produce such returns, more often than it should. To resolve this "inconsistency" we propose the low price correction by rounding the $\operatorname{PVaR}_{t}(p)$ estimate to the closest legitimate value, namely the next integer multiple of the $\mathrm{mpr}_{t}$.

Definition 5. Let $\operatorname{VVaR}_{t}(p)$ be the estimation of the $P V a R$ on day $t$ for a specific asset. The low price correction of the estimation denoted by $\widetilde{P V a R}_{t}(p)$ is given by:

$$
\widetilde{P \operatorname{VaR}}_{t}(p)=\left\{\begin{array}{cc}
\left(\left\lfloor\frac{P V a R_{t}(p)}{m p r_{t}}\right\rfloor+1\right) \cdot m p r_{t}, & \text { if } m p r_{t} \geq \Theta \\
P V a R_{t}(p) & \text { if } m p r_{t}<\Theta
\end{array}\right.
$$

where $\lfloor w\rfloor$ is the floor function (integer part) of $w$.

Observe that under the above low price correction the market's accuracy is passed on to the evaluation of the percentage value at risk resulting in a reasonable number of violations. 
International Journal of Mathematical, Engineering and Management Sciences

Vol. 4, No. 3, 542-566, 2019

https://dx.doi.org/10.33889/IJMEMS.2019.4.3-044

\subsection{Expected Percentage Shortfall (EPS) and Low Price Correction}

After we have obtained the $\operatorname{PVaR}_{t}(p)$, we calculate now the conditional expectation under $\operatorname{PVaR}_{t}(p)$, which is given by:

Definition 6. The expected percentage loss conditional on $\operatorname{PVaR}_{t}(p)$ being violated, is given by:

$$
E P S_{t}=-E\left[R_{t} \mid R_{t} \leq-R \operatorname{VaR}_{t}(p)\right]
$$

Observe that the area under $f(\cdot)$ in the interval $\left[-\infty,-P V a R_{t}(p)\right]$ is less than one, implying that $f(\cdot)$ is not a proper density function any more. This can be resolved by defining the tail density (right-truncated) function $f_{P V a R}(\cdot)$, obtained by truncation on the right, so that the area below, becomes exactly equal to 1 . Thus:

$$
\begin{aligned}
& 1=\int_{-\infty}^{\infty} f(x) d x \Rightarrow p=\int_{-\infty}^{-\operatorname{PVaR}_{t}(p)} f(x) d x \Rightarrow \\
& 1=\frac{1}{p} \int_{-\infty}^{-P V a R_{t}(p)} f(x) d x=\int_{-\infty}^{-P V a R_{t}(p)} f_{P V a R}(x) d x .
\end{aligned}
$$

The EPS is then given by:

$$
E P S_{t}=-E\left[R_{t} \mid R_{t} \leq-P V a R_{t}(p)\right]=-\int_{-\infty}^{-P V a R_{t}(p)} x f_{P V a R}(x) d x=-\frac{1}{p} \int_{-\infty}^{-P V a R_{t}(p)} x f(x) d x
$$

For providing the discrete expression of EPS, we present below the discretization $f_{D P V a R}(\cdot)$ of $f_{P V a R}(\cdot) . f_{D P V a R}(x)$ is the probability function of a discrete random variable, with values all possible returns under $\widehat{P V a R}_{t}(p)$, and probabilities given by:

$$
\begin{gathered}
f_{\text {DPVaR }}(x)=\int_{x}^{x+m p r} f_{P V a R}(x) d x=\int_{x}^{x+m p r} \frac{f(x)}{p} d x=\frac{1}{p} \int_{x}^{x+m p r} f(x) d x \\
=\frac{1}{p}[F(x+m p r)-F(x)],
\end{gathered}
$$

$x=-P \overline{V a R}_{t}(p)-m p r,-P \widetilde{V a R}_{t}(p)-2 m p r, \ldots$

Then, the definition of the discretization of EPS follows naturally.

Definition 7. Let $E P S_{t}$ be the estimation of the $E P S$ on day $t$ for a specific asset. The discrete approximation of the estimation $E P S_{t}$, denoted by $D E P S_{t}$, is given by:

$$
\operatorname{DEPS}_{t}=-\sum_{x \leq-P \widehat{\operatorname{VaR}}_{t}(p)} x f_{\text {DPVaR }}(x)
$$

where $f_{D P V a R}(\cdot)$ is the discretization of $f_{P V a R}(\cdot)$. 
International Journal of Mathematical, Engineering and Management Sciences

Vol. 4, No. 3, 542-566, 2019

https://dx.doi.org/10.33889/IJMEMS.2019.4.3-044

Remark 1. Even though, on the previous definition we call $D E P S_{t}$ the discrete approximation of $E P S_{t}$, the truth is that the nature of $f$ and by extension $f_{P V a R}$, is discrete, since there always exists a minimum possible return. We may treat returns as a continuous random variable when $m p r$ is extremely small, but the discrete nature of returns still exists.

Definition 8. Let $E P S_{t}$ be the estimation of the EPS on day $t$ for a specific asset. The low price correction of the estimation $E P S_{t}$ denoted by $\widehat{E P S}_{t}$, is given by:

$$
\widetilde{E P S_{t}}= \begin{cases}D E P S_{t}, & \text { if } m p r_{t} \geq \Theta \\ E P S_{t}, & \text { if } m p r_{t}<\Theta\end{cases}
$$

Remark 2. In the case of historical simulations, we take

$$
D_{E P S_{t}}=-\sum_{x \leq-P \overline{\operatorname{VaR}}_{t}(p)} x f_{E P V a R}(x),
$$

where $f_{E P V a R}(\cdot)$ is the discrete empirical probability function of $f_{P V a R}(\cdot)$ given by

$$
\begin{gathered}
f_{E P V a R}(x)=\frac{\text { number of historical observations such that } x \leq R_{i}<x+m p r_{t}, \text { for } i \leq t}{\text { number of historical observations such that } R_{i}<-P V a R_{t}(p)}, \\
x=-P \widetilde{V a R}_{t}(p)-m p r_{t},-P \widetilde{P a R}_{t}(p)-2 m p r_{t}, \ldots,-P \widetilde{V a R}_{t}(p)\left(\left[\frac{m_{i \leq t} R_{i}}{m p r_{t}}\right]+1\right) \cdot m p r_{t}
\end{gathered}
$$

where the $R_{i}$ 's are the realizations of returns.

\subsection{Evaluation Measures and Backtesting}

In order to evaluate the performance of the competing models, we will use statistical methods as well as backtesting. Popular evaluation measures used in the literature include the Mean Square Error (MSE), the Mean Absolute Error (MAE), and the Mean Absolute Percent Error (MAPE). Since the main interest lies on returns, which mostly (except for a very few extreme cases) take values in $(-0.5,0.5)$, we prefer MAE and MAPE, because the square will decrease further the errors. These measures should be appropriately adapted in order to capture the needs of the problem at hand.

Let $\left\{y_{t}\right\}_{t=1}^{T}$ be a sample of daily logarithmic losses on a trading portfolio. If, on a particular day, the logarithmic loss exceeds the PVaR forecast, then the PVaR limit is said to have been violated. For a given $\operatorname{PVaR}_{t}(p)$ we define the indicator $\eta_{t}$ that takes the value 1 if $y_{t}>\operatorname{PVaR}_{t}(p)$ (or $P \overline{\operatorname{VaR}}_{t}(p)$ if the correction has been enforced) and 0 otherwise.

A $P V a R$ violation is said to have occurred if $\eta_{t}=1$. Then, the observed frequency of violations over the total number of days $T$, the $P V a R$ forecast has been evaluated, is given by

$v(T)=\sum_{t \leq T} \eta_{t}$

Then the expressions for the evaluation measures used in this work are as follows: 
International Journal of Mathematical, Engineering and Management Sciences

Vol. 4, No. 3, 542-566, 2019

https://dx.doi.org/10.33889/IJMEMS.2019.4.3-044

3. MSE $=\frac{1}{v(T)} \sum_{t \leq T}\left(y_{t}-\operatorname{PVaR}_{t}(p)\right)^{2} \cdot \eta_{t}$

$$
M A E=\frac{1}{v(T)} \sum_{t \leq T}\left(y_{t}-\operatorname{PVaR}_{t}(p)\right)^{2} \cdot \eta_{t}
$$

and

$$
M A P E=\frac{1}{v(T)} \sum_{t \leq T}\left|\frac{100\left(y_{t}-P V a R_{t}(p)\right)}{y_{t}}\right| \cdot \eta_{t}
$$

A heteroskedasticity adjusted version of MSE denoted by HMSE (Bollerslev and Ghysels, 1996) is:

$$
H M S E=\frac{1}{v(T)} \sum_{t \leq T}\left[\frac{y_{t}}{P \operatorname{VaR} R_{t}(p)}-1\right]^{2} \cdot \eta_{\tau}
$$

in which case, the forecast error is scaled by the actual volatility.

Another way to evaluate the forecast ability of the model, is backtesting. In this work, we will use the violation ratio VR to backtest PVaR estimations, and normalised shortfall NS for backtesting EPS estimations. The comparison between the observed frequency and the expected number of violations provides the primary tool for backtesting, known as the violation ratio (Campbell, 2005) and is defined by:

Definition 9. Let $v(T)$ be the observed number of violations, $p$ the probability of a violation and $W_{T}$ the testing window. Then, the violation ratio $V R$ is defined by

$V R=\frac{\text { Observed number of violations }}{\text { Expected number of violations }}=\frac{v(T)}{p \times W_{T}}$.

Acceptable values for $V R$ according to Basel III accords lie in the region (0.8-1.2) while values over 1.5 or below 0.5 indicate imperfect modeling (see Danielsson, 2011).

It is harder to backtest expected percentage shortfall (EPS) than PVaR because we are testing an expectation rather than a single quantile. Fortunately, there exists a simple methodology for backtesting EPS that is analogous to the use of violation ratios for $P V a R$.

For each day $t$ when $P V a R$ is violated, the normalized shortfall $N S$ is calculated by

$$
N S_{t}=\frac{R_{t}}{E P S_{t}}
$$

where $E P S_{t}$ is the observed $E P S$ on day $t$. From the definition of $E P S$, the expected return, given that $P V a R$ is violated, is: 
International Journal of Mathematical, Engineering and Management Sciences

Vol. 4, No. 3, 542-566, 2019

https://dx.doi.org/10.33889/IJMEMS.2019.4.3-044

$$
\frac{E\left[R_{t} \mid R_{t} \leq P \operatorname{VaR} R_{t}(p)\right]}{E P S_{t}}=1
$$

Therefore, average $N S$, denoted by $\overline{N S}$, given by:

$$
\overline{N S}=\frac{1}{n} \sum_{t=1}^{n} N S_{t}=\frac{1}{n} \sum_{t=1}^{n} \frac{R_{t}}{E P S_{t}}
$$

should be equal to one which in turn, formulates the null hypothesis

$$
H_{0}: \overline{N S}=1 \text {. }
$$

With EPS, we are testing whether the mean of returns on days when PVaR is violated is the same as the expected $E P S$ on these days. As it is clear, it is much harder to create a formal test in order to ascertain, whether normalized EPS equals to one or not. Such a test would have to simultaneously test the accuracy of $P V a R$ and the expectation beyond $P V a R$. This means that the reliability of any EPS backtest procedure is likely to be much lower than that of PVaR backtest procedures.

\section{Application}

The stocks in Table 1, gathered from Nasdaq, NYSE and NYSE MKT (picked from investopedia.com and personalincome.com for the period 1/2008 to 12/2017) meet the requirements needed for lpe, i.e., they demonstrate prices between 1 to 10 dollars. For illustrative and comparative purposes ENRJ and NAK from NYSE MKT, are fully examined for the period 8/1/2008 - 8/12/2017 (2500 observations). Note that we concentrate on the above stocks not only because they are representative examples of the lpe, but also because they have the highest proportion of values falling within the lpe area and as a result they are expected to demonstrate more clearly than others the contribution of the low price correction into the proper evaluation of risk. Also, in order to show the generality of our method, and that in the case of derivatives, it is extremely useful, we examine the case of NBG warrants which is a representative example of the behaviour of low price correction in derivatives. 
International Journal of Mathematical, Engineering and Management Sciences

Vol. 4, No. 3, 542-566, 2019

https://dx.doi.org/10.33889/IJMEMS.2019.4.3-044

Table 1. Stocks where lpe is present

\begin{tabular}{|l|c|c|c|c|}
\hline \multicolumn{1}{|c|}{ Stock Name } & Abbr. & Min Adj. Close & Max Adj. Close & Index \\
\hline Arotech Corporation & ARTX & 0.38 & 6.25 & Nasdaq \\
\hline Central European Media Enterprises Ltd. & CETV & 0.4292 & 23.5636 & Nasdaq \\
\hline EnerJex Resources, Inc. & ENRJ & 0.200 & 90.000 & NYSE MKT \\
\hline EVINE Live Inc. & EVLV & 0.180 & 8.620 & Nasdaq \\
\hline Glu Mobile Inc. & GLUU & 0.230 & 7.470 & Nasdaq \\
\hline Hecla Mining Company & HL & 1.014 & 12.577 & NYSE \\
\hline Kingold Jewelry, Inc. & KGJ & 0.05628 & 9.94264 & Nasdaq \\
\hline Limelight Networks, Inc. & LLNW & 0.900 & 8.430 & Nasdaq \\
\hline Ladenburg Thalmann Financial Services Inc. & LTS & 0.3984 & 4.4325 & NYSE MKT \\
\hline MannKind Corporation & MNKD & 0.71 & 59.05 & Nasdaq \\
\hline Medical Transcription Billing, Corp & MTBC & 0.390 & 4.280 & Nasdaq \\
\hline Mueller Water Products, Inc. & MWA & 1.378 & 13.864 & NYSE \\
\hline Northern Dynasty Minerals, Ltd. & NAK & 0.210 & 21.080 & NYSE MKT \\
\hline Plug Power Inc. & PLUG & 0.12 & 43.90 & Nasdaq \\
\hline Sierra Oncology, Inc. & SRRA & 1.120 & 31.320 & Nasdaq \\
\hline United Microelectronics Corporation & UMC & 1.084 & 3.031 & NYSE \\
\hline UQM Technologies, Inc. & UQM & 0.430 & 7.030 & NYSE MKT \\
\hline EXCO Resources, Inc. & XCO & 0.52 & 508.00 & NYSE \\
\hline Zix Corporation & ZIXI & 0.910 & 6.610 & Nasdaq \\
\hline
\end{tabular}

Siouris and Karagrigoriou (2017) implemented the low price correction (lpc) methodology on the National Bank of Greece (NBG) stock from the banking index of the Athens Stock Exchange (ASE or ATHEX). The choice emanates from the fact that NBG stock has exhibited violent changes in its price, as well as volatility structural changes because of the economic environment under which it operates. Indeed, the stock experienced the impact of extreme economic events like the bubble of 1999, the economic crises of 2007-2009, the entrance of Greece on the IMF program on 23/4/2010 and the enforcement of capital controls on 29/6/2015.

For modelling purposes we fit the following GARCH family models which are evaluated and compared for identifying those that work better:

- $\mathrm{ARCH}(1), \mathrm{ARCH}(4)$ and ARCH(5) with normal innovations

- GARCH( $(1,1)$ with normal and t-Student innovations

- $\operatorname{GARCH}(1,1),(4,1),(5,1),(2,2)$ and $(3,2)$ with skew t-Student innovations

- APARCH(1,1) with Normal, t-Student and skew t-Student innovations and with Normal innovations and $\delta=2$,

- $\operatorname{APARCH}(2,2)$ with Normal, t-Student and skew t-Student innovations

- IGARCH $(1,1)$ with and without a constant and with a constant with Student's t innovations

- $\operatorname{FIGARCH}(0, \mathrm{~d}, 0),(1, \mathrm{~d}, 0),(0, \mathrm{~d}, 1),(1, \mathrm{~d}, 1)$ and $(1, \mathrm{~d}, 1)$ with Student's t Errors.

It should be noted that the data, before being fitted, were multiplied by 100 and demeaned.

Using model selection identification techniques like AIC and BIC and investigated the statistical significance of the parameter estimates, we conclude that $\operatorname{GARCH}(1,1), \operatorname{GARCH}(2,2)$ and APARCH $(1,1)$ all with skew t-Student innovations are the models that perform better than the rest. For the evaluation of the predictive ability, the above three models together with the standard choices of HS, VaR estimation under normality and EWMA, were compared by backtesting, using 
International Journal of Mathematical, Engineering and Management Sciences

Vol. 4, No. 3, 542-566, 2019

https://dx.doi.org/10.33889/IJMEMS.2019.4.3-044

the Violation Ratio (VR) and the Normalized Shortfall (NS) as described in section 2.3. Note that the existence of the expected shortfall is guaranteed since in our analysis, we rely on distributions with tail's fatness up to Student $t$ with 2 degrees of freedom (Broda and Paolella, 2011).

\section{a. The Case of the NBG Warrants}

Warrants are in many ways similar to options, but with a few key differences distinguishing them. Warrants are in general issued by the company itself, not a third party and they are traded over-thecounter more often than on an exchange market. Warrants cannot be written by investors, like in the case of options, and they tend to have much longer periods between issue and expiration. They do not pay dividends or come with voting rights. Investors are attracted to warrants as a means of leveraging their positions in a security, hedging against downside or exploiting arbitrage opportunities.

In our case, the warrants of National Bank of Greece (NBG) were issued in 2013, due to the first recapitalization of the Greek banking system, and were traded on the Athens Stock Exchange (ASE or ATHEX). The expiration date of the warrants was for 4.5 years from the issue date. They had 9 exercise dates, one every six months. In every exercise date the owner could buy stocks on a specific price, which in the case of the NBG was 4.6761 euros per stock. Since later on NBG's stock price collapsed, warrants' price also collapsed.

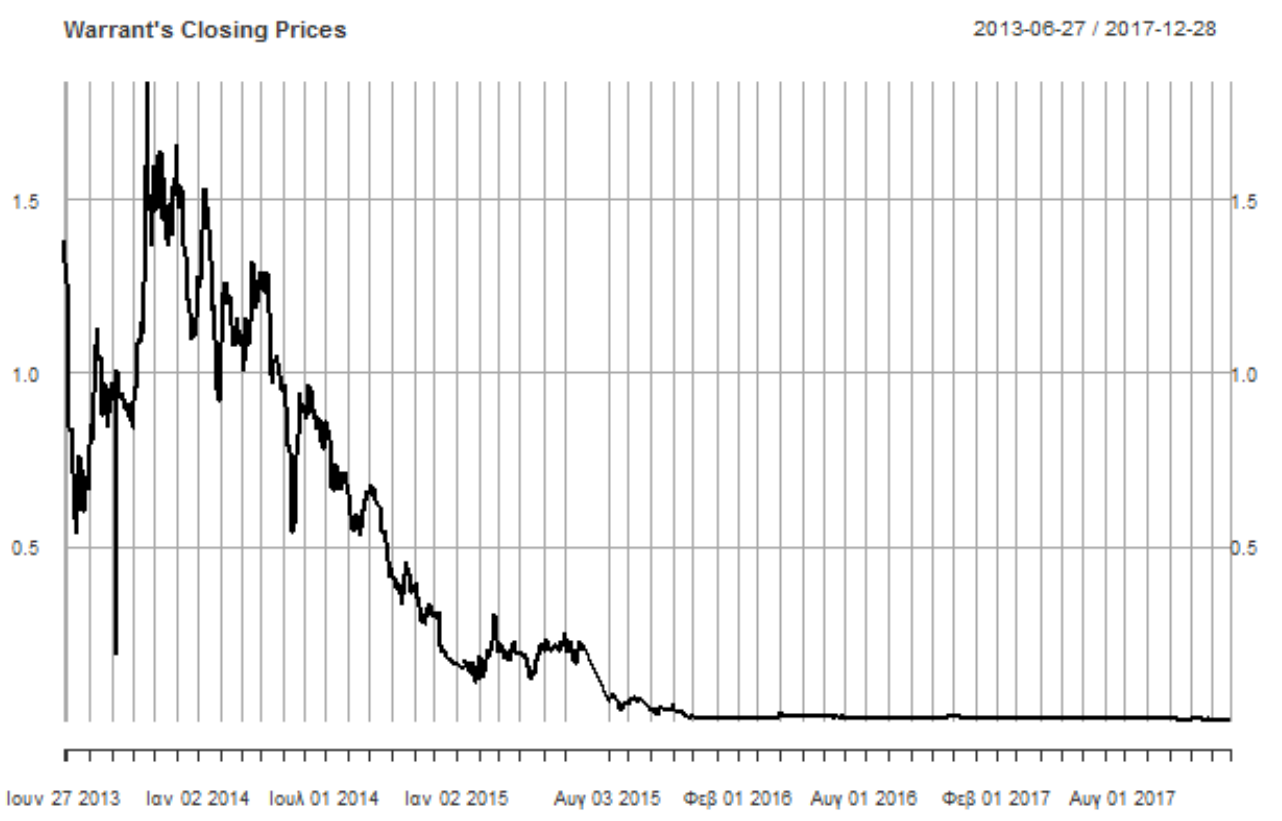

Figure 1. NBG warrants-clossing prices (2013-2017) 
International Journal of Mathematical, Engineering and Management Sciences

Vol. 4, No. 3, 542-566, 2019

https://dx.doi.org/10.33889/IJMEMS.2019.4.3-044

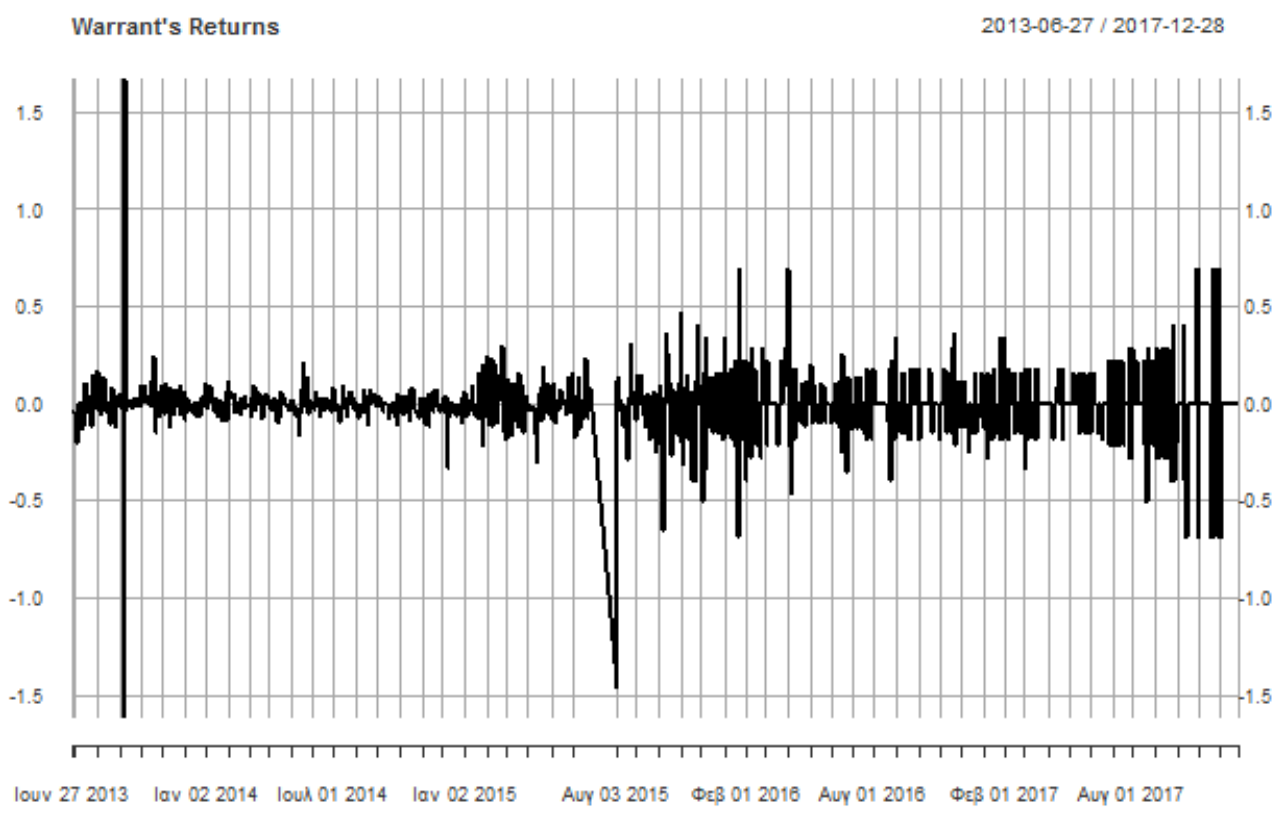

Figure 2. NBG warrants - returns (2013-2017)

Figures 1 and 2 provide the general idea of the warrant price movement over the 4.5 years. This asset was especially chosen for its extreme movements, while it also meets the requirements needed for lpe. Its extreme low prices in the recent years, make it a perfect example for the low price correction methodology.

The daily return mean is negligible, $-0.65 \%$, while daily volatility is $16 \%$. The fact that the daily mean is minor, contrary to a comparatively greater volatility, will simplify the construction of volatility models as we can assume that mean is zero, without loss of generality. The returns have a negative skewness of -0.59 , but more importantly, they have an excessive kurtosis of 30.4 , which is our clue for expecting fat tails.

The returns have a quite high and negative daily autocorrelation of $-26.46 \%$ (which is quite rare since it usually is almost zero), while squared returns (which are a proxy for volatility) have an even higher autocorrelation of $35.7 \%$, which provides very strong evidence of the predictability of volatility and the existence of volatility clusters. For the latter, the Engle's Lagrange Multiplier test for 20 lags indicates that the null hypothesis is rejected, i.e., there is no predictability in the ARCH volatility model hence volatility clusters are present (test statistic $=151.16$, p-value $<2.2 \times 10^{-16}$ ).

According to the autocorrelation function (ACF) of daily returns for 20 lags and squared daily returns for 100 lags respectively (figures not shown), there is little dependence between successive returns and squared returns. This provides some evidence, that GARCH and APARCH models may not be appropriate. 
International Journal of Mathematical, Engineering and Management Sciences

Vol. 4, No. 3, 542-566, 2019

https://dx.doi.org/10.33889/IJMEMS.2019.4.3-044

The Ljung-Box (LB) test was used in order to test for the joint significance of autocorrelation coefficients over several lags. We run it using 20 lags of daily returns, as well as 20 lags of squared daily returns. Results show that there is significant return predictability for both cases. However, the test statistic for the squared daily returns is much higher $\left(X^{2}=146.88\right)$ than that of the daily returns $\left(X^{2}=94.978\right)$. The LB test $\mathrm{p}$-values are smaller than the accuracy under which $R$ generally evaluates p-values $\left(<2.2 \times 10^{-16}\right)$, that is why we take into account the test statistics. Hence, we conclude that it is easier to predict volatility than the returns.

For the distribution of returns, the Q-Q plots for the Normal and Student $\mathrm{t}$ with 2 and 4 degrees of freedom (df) are also furnished (Figures 3-5). The plots clearly show that the underlying distribution is not normal, since the tails do not fit. The deviation from normality has also been confirmed via the Jarque-Bera test $\left(\left(X^{2}=34466, p-\right.\right.$ value $\left.<2.2 \times 10^{-16}\right)$. The Student $\mathrm{t}$ distribution with $4 \mathrm{df}$ also seems not to have fat enough tails. Finally, the Student t with $2 \mathrm{df}$ seems to be closer in capturing the fatness of the tails, yet it still does not do so satisfactorily. However, in our study Student $t$ with 3 df distribution will be assumed, as it has definable variance.

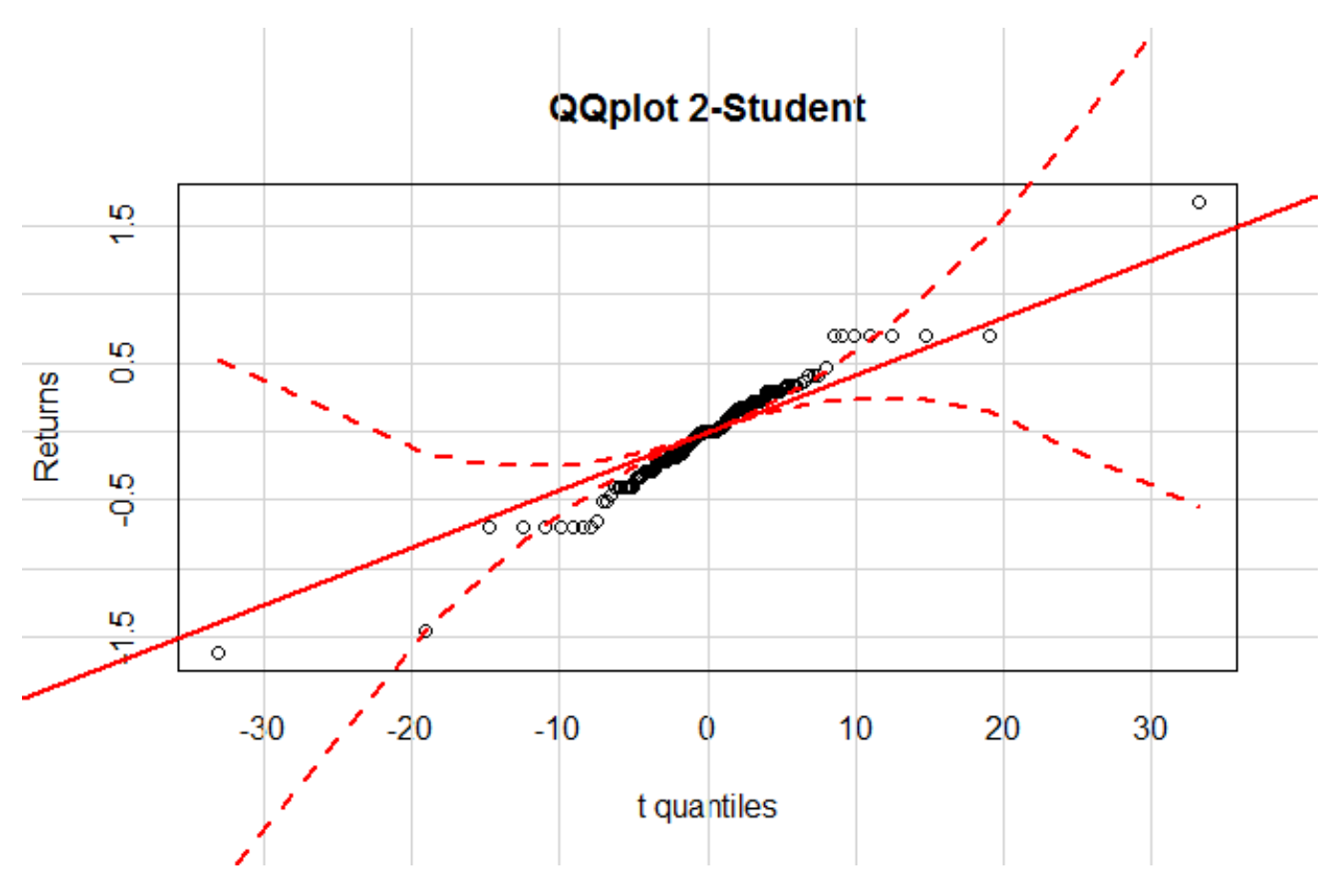

Figure 3. Q-Q normal distribution 
International Journal of Mathematical, Engineering and Management Sciences

Vol. 4, No. 3, 542-566, 2019

https://dx.doi.org/10.33889/IJMEMS.2019.4.3-044

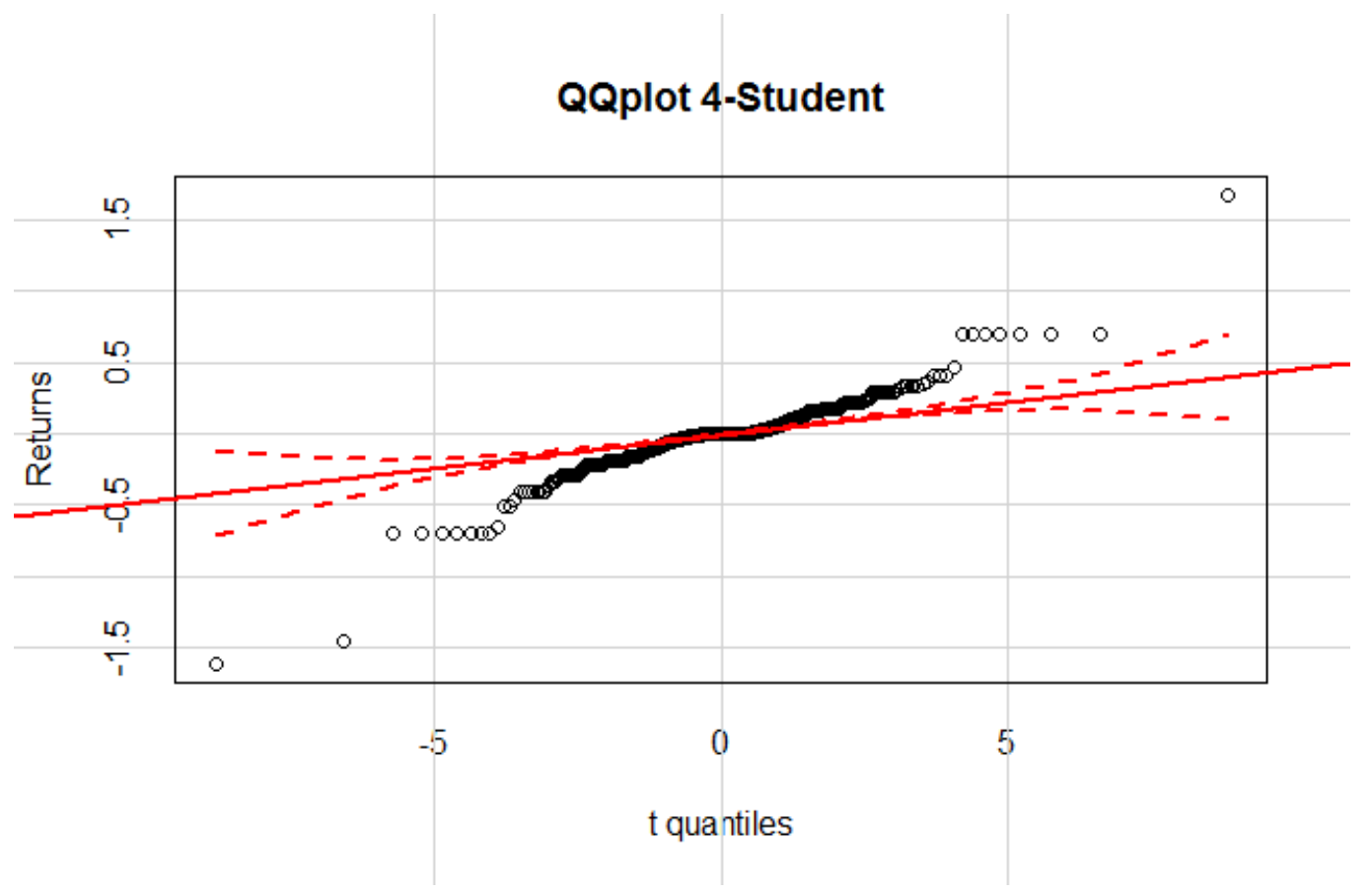

Figure 4. Q-Q 2-student distribution

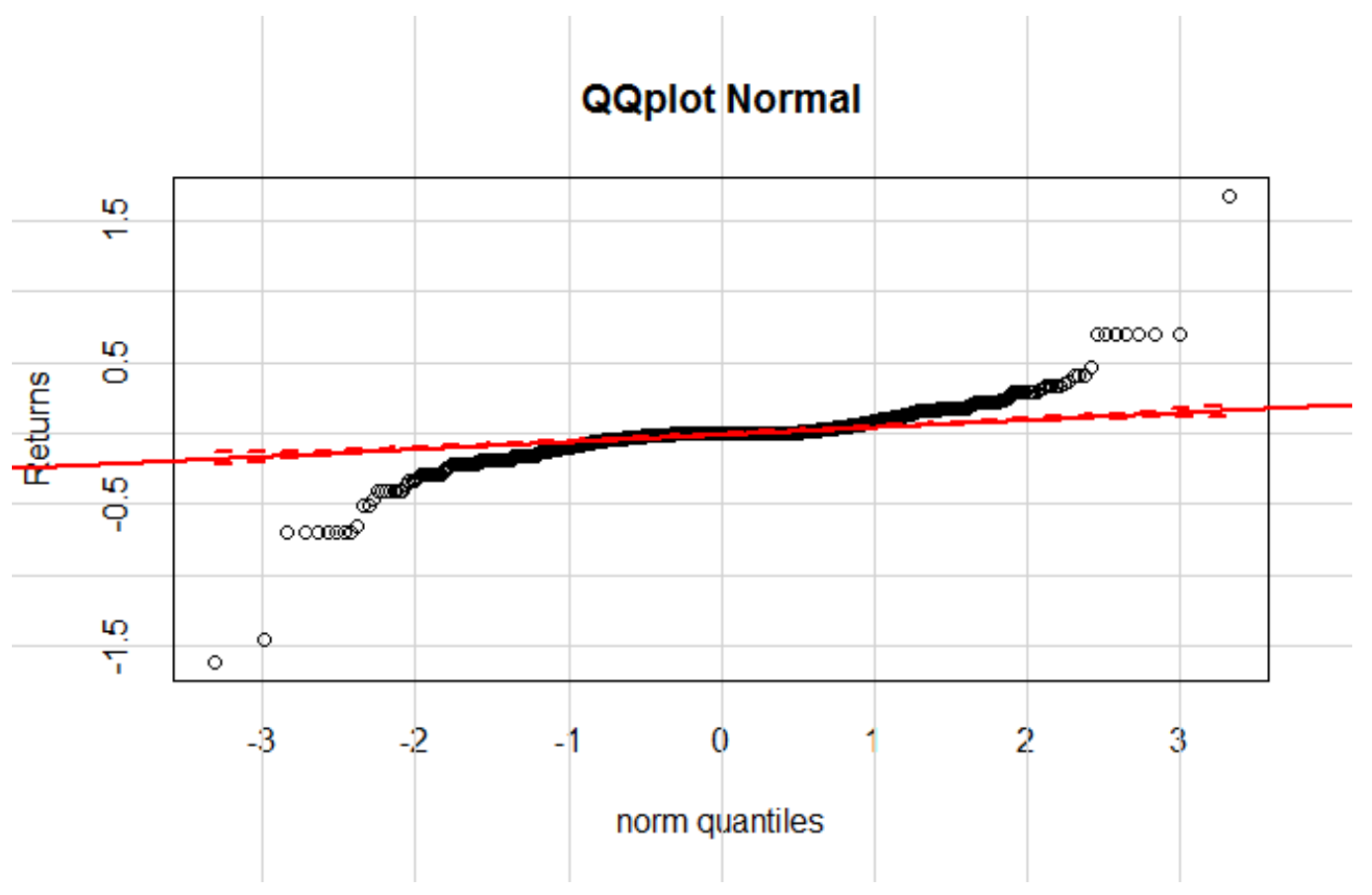

Figure 5. Q-Q 4-student distribution 
International Journal of Mathematical, Engineering and Management Sciences

Vol. 4, No. 3, 542-566, 2019

https://dx.doi.org/10.33889/IJMEMS.2019.4.3-044

For evaluating the applicability as well as the effectiveness of the proposed low price effect approach on the NBG warrants, we run the models and the respective backtesting twice in the last part of the series where the threshold for the low price effect has been surpassed, which occurred on 25/04/2014 leaving 894 available values until 28/12/2017, when NBG warrants were expired. The complete dataset (1099 observations) extend from 27/6/2013 until 28/12/2017.

Table 2. Backtesting with and without lpc for PVaR NBG warrants

\begin{tabular}{|c|c|c|c|c|}
\hline & VR without lpc & PVaR vol without lpc & VR with lpc & PVaR vol with lpc \\
\hline EWMA & 1.414141 & 0.1224841 & 0.8754209 & 0.1701248 \\
\hline Normal & 1.436588 & 0.08374533 & 0.9876543 & 0.1390613 \\
\hline HS & 1.885522 & 0.08965133 & 1.234568 & 0.1495181 \\
\hline GARCH(1,1) & 1.818182 & 0.1204021 & 1.257015 & 0.1731923 \\
\hline
\end{tabular}

The results of Violation Ratio backtesting for the two runs, one without and one with the low price correction, are shown in Table 2. The low price correction was implemented based on Definition 5 for $\Theta=0.1 \%$ and $p=0.05$. The investigation for other popular percentiles, is left for future work. The results clearly show that if the low price effect is taken into consideration in backtesting, the Violation Ratio (VR) is always improved in the sense that the frequency of violations is reduced, which is implying a more defensive approach in accordance with Basel III. Indeed, observe that in all cases, the observed number of violations has been reduced and as a result the violation ratio is improved. We also observe that PVaR volatility fails to show any improvement, rather it is slightly increased, yet not dramatically.

In addition, all applied models after the correction, yield acceptable or almost acceptable VRs (where the acceptable range is considered within the interval $0.8-1.2$ ).

For the aforementioned models we also calculate the evaluation measures introduced in Section 2.3 as well as the standard evaluation measures. The results are given in Tables 3-5. Since we work with returns which have an absolute value smaller than 1 , the most appropriate measures are MAE and MAPE. Table 3 contains the standard evaluation measure results for $P V a R$, with and without low price correction, which as it is clear fail to capture the improvement in forecasting ability which is evident by VR. This is due to the fact that $P V a R$ is a percentile estimation. Table 4 provides the evaluation measure results for $P V a R$, with and without low price correction, according to the violations of each model, which which also fail to capture the improvement in forecasting ability which is evident by VR. This is due to the difference in the denominator, which make the numbers impossible to be compared. Lastly, Table 5 contains the evaluation measure results for PVaR, with and without low price correction, according only to the violations of the model "with lpe". This is not unreasonable since the violations of the improved model are always fewer than those of the initial one. 
International Journal of Mathematical, Engineering and Management Sciences

Vol. 4, No. 3, 542-566, 2019

https://dx.doi.org/10.33889/IJMEMS.2019.4.3-044

Table 3. Evaluation measures results for PVaR with and without lpc of NBG warrants - 1

\begin{tabular}{|c|c|c|c|c|c|}
\hline & MSE & MAE & MAPE & HMSE & \# of Violations \\
\hline EWMA & 0.08959510 & 0.2345721 & 283.0198 & 1.414714 & 891 \\
\hline EWMA (lpc) & 0.13321386 & 0.2882063 & 296.3516 & 1.312602 & 891 \\
\hline Normal & 0.07842356 & 0.2313674 & 335.4894 & 1.499397 & 891 \\
\hline Normal (lpc) & 0.11700468 & 0.2815343 & 348.1618 & 1.366298 & 891 \\
\hline HS & 0.06918058 & 0.2083804 & 233.1994 & 1.627136 & 891 \\
\hline HS (lpc) & 0.10728055 & 0.2591924 & 245.8914 & 1.476536 & 891 \\
\hline GARCH(1,1) & 0.07873061 & 0.2113150 & 256.1190 & 2.746523 & 891 \\
\hline GARCH(1,1)(lpc) & 0.12377995 & 0.2687740 & 268.0334 & 1.373017 & 891 \\
\hline
\end{tabular}

Table 4. Evaluation measures results for PVaR with and without lpc of NBG warrants -2

\begin{tabular}{|c|c|c|c|c|c|}
\hline & MSE & MAE & MAPE & HMSE & \# of Violations \\
\hline EWMA & 0.04454162 & 0.10670786 & 27.19767 & 1.679775 & 63 \\
\hline EWMA (lpc) & 0.05632466 & 0.09550818 & 24.05620 & 2.408766 & 39 \\
\hline Normal & 0.05569806 & 0.13136742 & 29.03018 & 1.924203 & 64 \\
\hline Normal (lpc) & 0.05046753 & 0.08729689 & 19.76906 & 2.075661 & 44 \\
\hline HS & 0.04582400 & 0.11644768 & 29.33722 & 1.929689 & 84 \\
\hline HS (lpc) & 0.04486931 & 0.09170765 & 25.06878 & 2.299259 & 55 \\
\hline GARCH(1,1) & 0.05232076 & 0.12790622 & 35.75844 & 9.692231 & 81 \\
\hline GARCH(1,1) (lpc) & 0.04195689 & 0.08042647 & 21.16355 & 1.881913 & 56 \\
\hline
\end{tabular}

Table 5. Evaluation measures results for PVaR with and without lpc of NBG warrants - 3

\begin{tabular}{|c|c|c|c|c|c|}
\hline & MSE & MAE & MAPE & HMSE & \# of Violations \\
\hline EWMA & 0.06993500 & 0.14457923 & 33.78901 & 2.658553 & 39 \\
\hline EWMA (lpc) & 0.05632466 & 0.09550818 & 24.05620 & 2.408766 & 39 \\
\hline Normal & 0.07788985 & 0.16334422 & 34.04885 & 2.742979 & 44 \\
\hline Normal (lpc) & 0.05046753 & 0.08729689 & 19.76906 & 2.075661 & 44 \\
\hline HS & 0.06790716 & 0.15499175 & 37.27808 & 2.908765 & 55 \\
\hline HS (lpc) & 0.04486931 & 0.09170765 & 25.06878 & 2.299259 & 55 \\
\hline GARCH(1,1) & 0.07232273 & 0.15283203 & 37.89425 & 10.886520 & 56 \\
\hline GARCH(1,1) (lpc) & 0.04195689 & 0.08042647 & 21.16355 & 1.881913 & 56 \\
\hline
\end{tabular}


International Journal of Mathematical, Engineering and Management Sciences

Vol. 4, No. 3, 542-566, 2019

https://dx.doi.org/10.33889/IJMEMS.2019.4.3-044

As it is clear by Table 5, lpc produces a genuine improvement for all models in all measures. The choice of this specific subset to compute the evaluation measures is not unreasonable, since from the risk management point of view only the days of violations are the most important ones. Decreasing the error on these days translates to decreasing the loss at days that loss exceeds what we are prepared for. Hence, this clear improvement is incredible important. According to these results, we conclude that low price correction, significantly improves the estimation of risk for all models. This decrease was expected, since the methodology of low price correction, always provides improved estimations as well as "logical" ${ }^{1}$ ones, for every model.

Finally, we have backtested Expected Percentage Shortfall (EPS) with the method of normalised shortfall (NS), i.e., with and without lpe taken into account. For comparative purposes, Table 6 contains the VRs of the PVaR estimations, as well as, NSs of the EPS estimations. Backtesting results clearly show the improvement by the implementation of the low price correction.

Although the number of violations has decreased significantly, as shown in the decrease of the VRs of the PVaR estimations, the NS of EPS seems to be slightly increased. This is due to the fact that the violations that still occurred after the low price correction, were the most extreme ones, and hence, the increase of EPS is expected. This increase is minor and as a result, we succeeded in retaining the NS of EPS in an acceptable range around 1, while significantly improving the VR of PVaR.

Table 6. Backtest results for Historic Simulation with and without lpc for EPS (NBG warrants)

\begin{tabular}{|c|c|c|}
\hline & Without lpc & With lpc \\
\hline HS PVaR's VR & 1.885522 & 1.234568 \\
\hline HS EPS's NS & 1.064291 & 1.221529 \\
\hline
\end{tabular}

\section{b. The Case of the ENRJ Stock}

Our methodology will be also implemented on the EnerJex Resources, Inc. (ENRJ) stock from the Independent Oil and Gas index of the American Stock Exchange (NYSE MKT). The data (2500 observations) extend from 8/1/2008 until 8/12/2017.

\footnotetext{
${ }^{1}$ Logical in the sense that any irrational answer from the models, is rationalized in the next possible return.
} 
International Journal of Mathematical, Engineering and Management Sciences

Vol. 4, No. 3, 542-566, 2019

https://dx.doi.org/10.33889/IJMEMS.2019.4.3-044

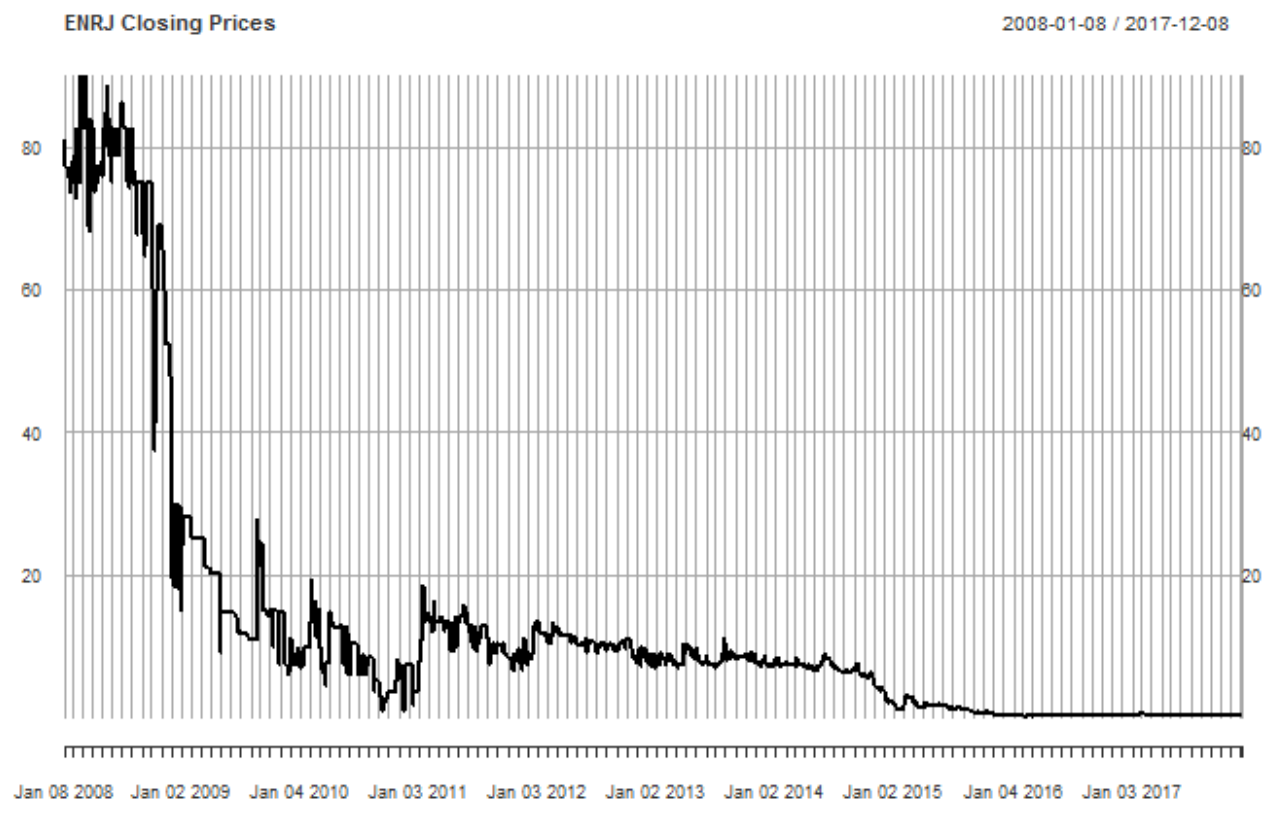

Figure 6. ENRJ closing prices (2008-2017)

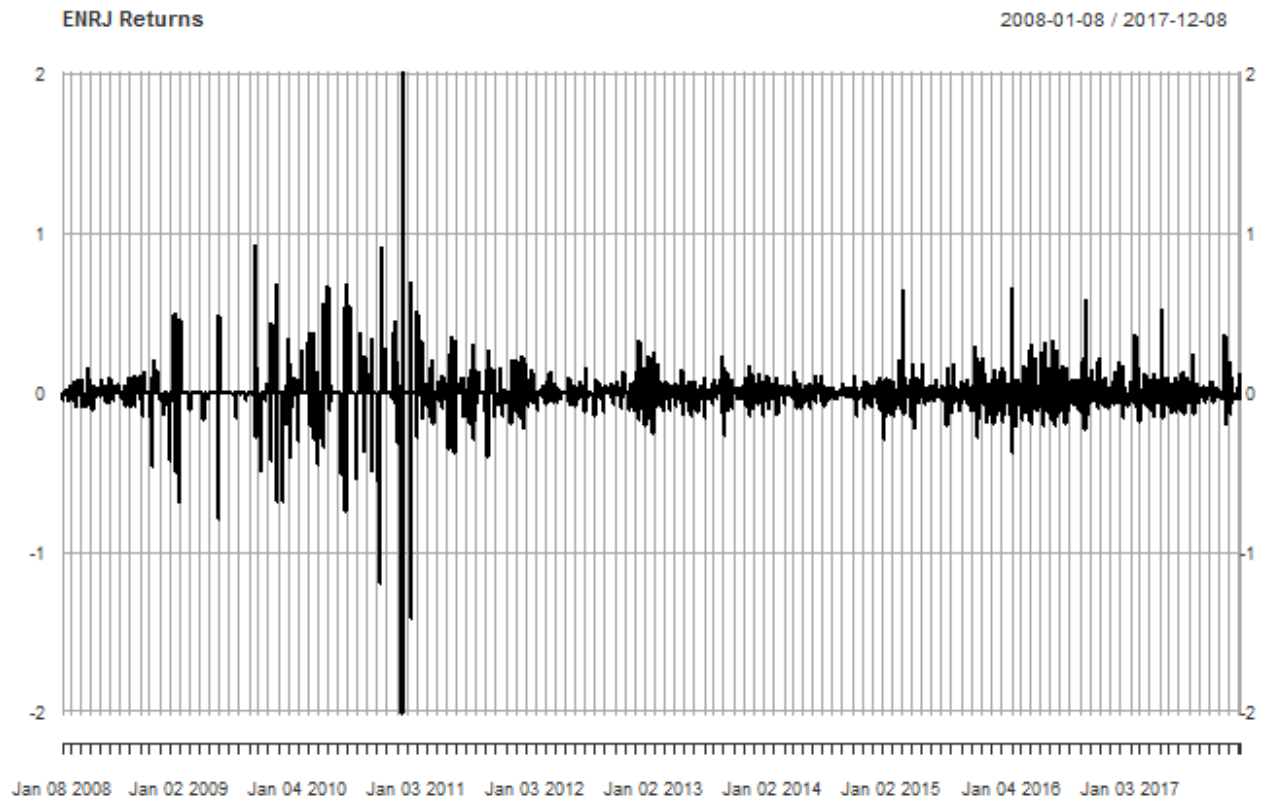

Figure 7. ENRJ returns (2008-2017) 
International Journal of Mathematical, Engineering and Management Sciences

Vol. 4, No. 3, 542-566, 2019

https://dx.doi.org/10.33889/IJMEMS.2019.4.3-044

Figures 6 and 7 provide the general idea of the stock price movement over the last 10 years. This stock was especially chosen for its extreme movements in the last ten years, while it also meets the requirements needed for lpe. Its extreme low prices in recent years, makes it a perfect example for the low price correction methodology. The results for the evaluation measures appear in Table 7.

As it was expected, the number of violations is significantly decreased in all cases. The behaviour of the lpc is exactly the same as before. According to these results, we conclude that the low price correction, significantly improves the estimation of risk for all models.

Table 7. Evaluation measures results for PVaR with and without lpc ENRJ - 3

\begin{tabular}{|c|c|c|c|c|c|}
\hline & MSE & MAE & MAPE & HMSE & \# of Violations \\
\hline EWMA & 0.003868305 & 0.04196150 & 25.02865 & 0.4458413 & 84 \\
\hline EWMA (lpc) & 0.003795848 & 0.04122138 & 24.43562 & 0.4186452 & 84 \\
\hline Normal & 0.004710667 & 0.04790230 & 23.96224 & 0.3547995 & 60 \\
\hline Normal (lpc) & 0.004624179 & 0.04709806 & 23.41807 & 0.3389335 & 60 \\
\hline HS & 0.005108696 & 0.04924716 & 23.59509 & 0.3259856 & 76 \\
\hline HS (lpc) & 0.005049115 & 0.04855851 & 23.13867 & 0.3177697 & 76 \\
\hline GARCH(1,1) & 0.005700902 & 0.05411329 & 48.11248 & 25.8266898 & 182 \\
\hline GARCH(1,1)(lpc) & 0.005640090 & 0.05361578 & 47.59685 & 23.2312156 & 182 \\
\hline GARCH(2,2) & 0.005697607 & 0.05369836 & 48.11274 & 26.4580090 & 179 \\
\hline GARCH(2,2)(lpc) & 0.005631055 & 0.05310253 & 47.54432 & 23.4711763 & 179 \\
\hline
\end{tabular}

The backtest results for the Expected Percentage Shortfall (EPS) with the method of normalised shortfall (NS) and for the PVaR with the method of violation ratio (VR) appear at the end of the next subsection together for ENRJ and NAK stocks.

\section{c. The case of the NAK stock}

Our methodology will finally be implemented on the Northern Dynasty Minerals, Ltd. (NAK) stock from the industrial metals and minerals index of the American Stock Exchange (NYSE MKT). The data (2500 observations) extend from 8/1/2008 until 8/12/2017. 
International Journal of Mathematical, Engineering and Management Sciences

Vol. 4, No. 3, 542-566, 2019

https://dx.doi.org/10.33889/IJMEMS.2019.4.3-044

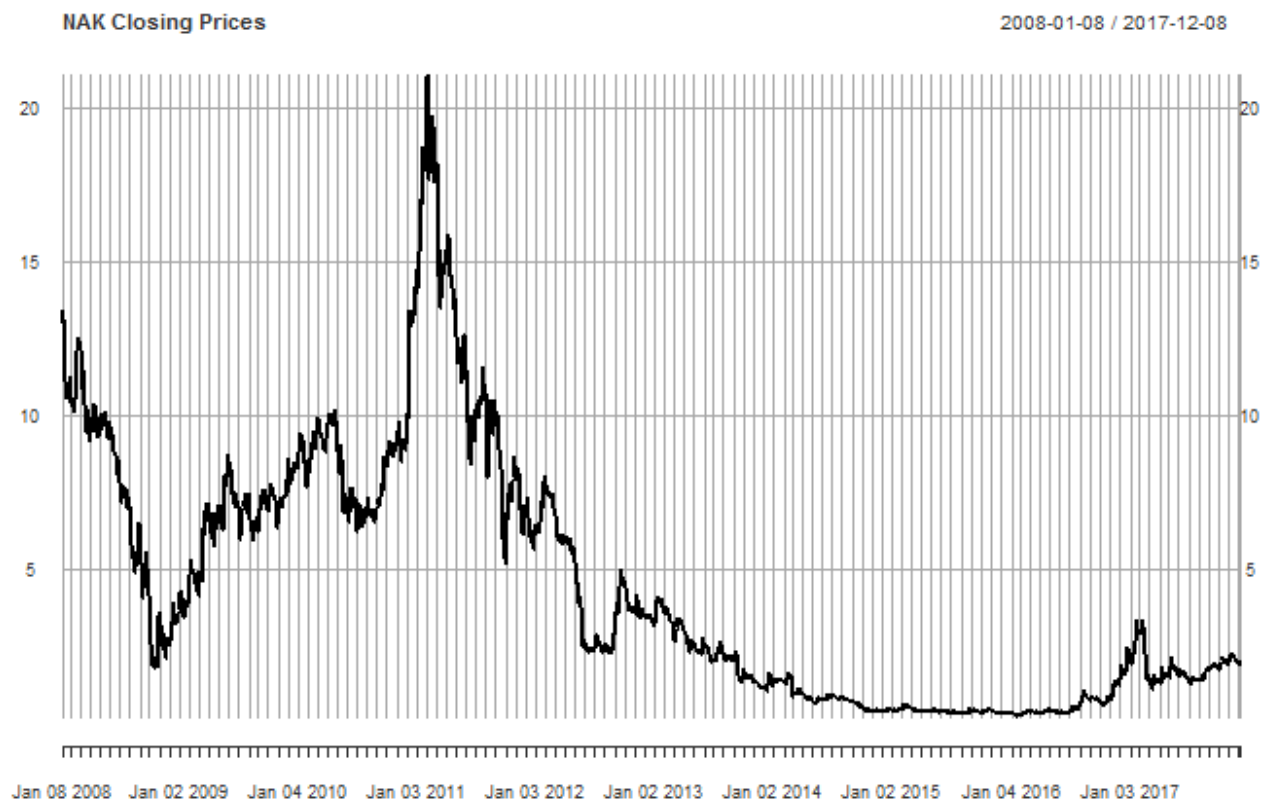

Figure 8. NAK Closing Prices (2008-2017)

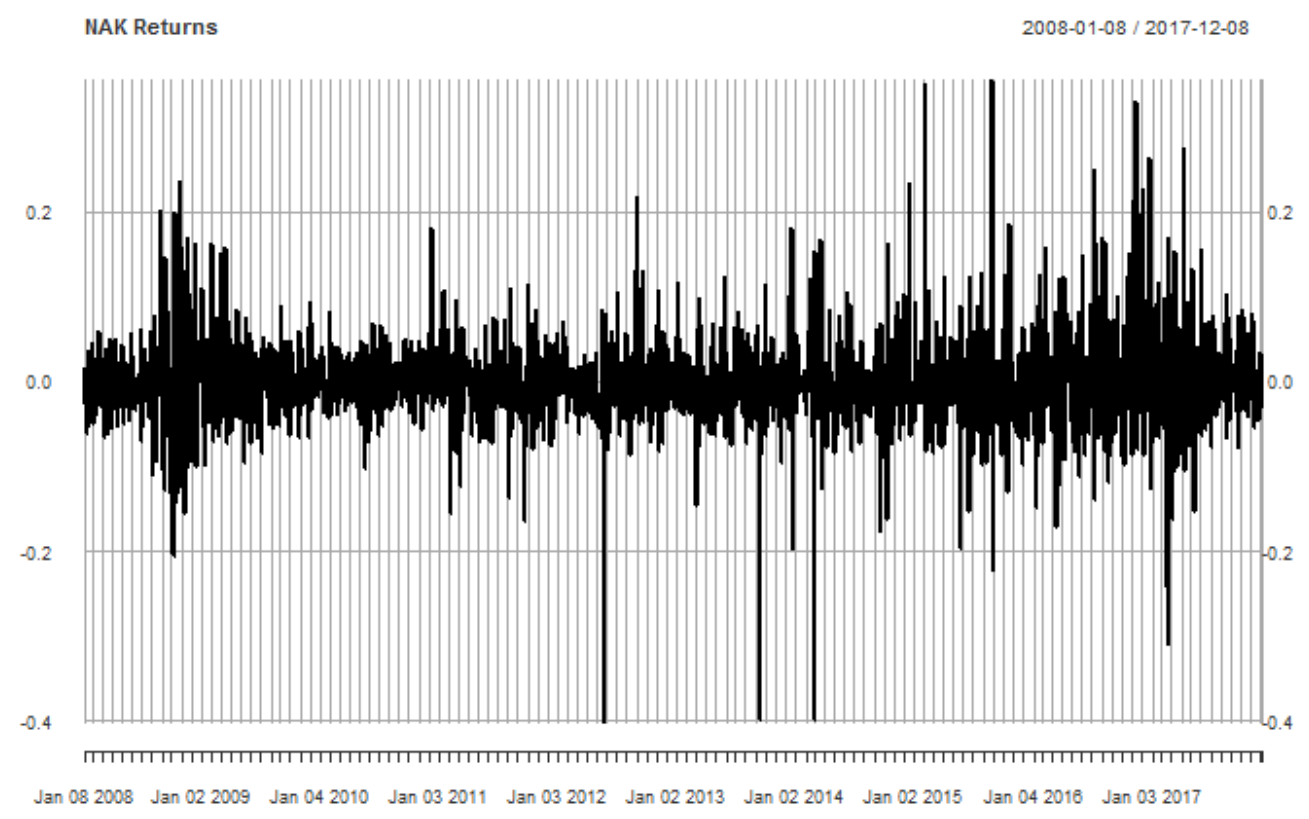

Figure 9. NAK returns (2008-2017) 
International Journal of Mathematical, Engineering and Management Sciences

Vol. 4, No. 3, 542-566, 2019

https://dx.doi.org/10.33889/IJMEMS.2019.4.3-044

Figures 8 and 9 provide the general idea of the stock price movement over the last 10 years. This stock also exhibits extreme shifts, as well as, prices in the low prices effect area. The results for the evaluation measures provided in Table 8 show the considerable improvement due to the low price correction in all cases.

Table 8. Standard evaluation measures results for PVaR with and without lpc of NAK - 3

\begin{tabular}{|c|c|c|c|c|c|}
\hline & MSE & MAE & MAPE & HMSE & \# of Violations \\
\hline EWMA & 0.007756672 & 0.04519538 & 26.38935 & 1.965658 & 65 \\
\hline EWMA (lpc) & 0.007639877 & 0.04418522 & 25.19443 & 1.837000 & 65 \\
\hline Normal & 0.008682149 & 0.05233320 & 27.17981 & 1.679915 & 60 \\
\hline Normal (lpc) & 0.008505468 & 0.05119064 & 26.16090 & 1.530473 & 60 \\
\hline HS & 0.006178286 & 0.04263564 & 27.17236 & 1.471903 & 99 \\
\hline HS (lpc) & 0.006074069 & 0.04175005 & 26.25985 & 1.363650 & 99 \\
\hline GARCH(1,1) & 0.006406549 & 0.04219355 & 28.24221 & 1.935671 & 89 \\
\hline GARCH(1,1)(lpc) & 0.006277397 & 0.04128416 & 27.30712 & 1.779717 & 89 \\
\hline GARCH(2,2) & 0.006860086 & 0.04500551 & 30.09218 & 2.062461 & 83 \\
\hline GARCH(2,2)(lpc) & 0.006719502 & 0.04402593 & 29.09760 & 1.900888 & 83 \\
\hline APARCH(1,1) & 0.006472701 & 0.04313437 & 28.76565 & 2.104373 & 90 \\
\hline APARCH(1,1)(lpc) & 0.006370651 & 0.04217833 & 27.69914 & 1.958707 & 90 \\
\hline
\end{tabular}

As it was expected, the number of violations is significantly decreased in all cases. The behaviour of the lpc is exactly the same as before. According to these results, we conclude that low price correction, significantly improves the estimation of risk for all models.

Finally, the backtest results appear in Tables 9 and 10. For comparative purposes, Table 10 contains the VRs of the PVaR estimations, as well as, NSs of the EPS estimations. Backtesting results clearly show the improvement by the implementation of the low price correction. 
International Journal of Mathematical, Engineering and Management Sciences

Vol. 4, No. 3, 542-566, 2019

https://dx.doi.org/10.33889/IJMEMS.2019.4.3-044

Table 9. Backtesting with and without lpc for PVaR

\begin{tabular}{|c|c|c|c|c|}
\hline & VR without lpe & PVaR vol without lpc & VR with lpe & PVaR vol with lpc \\
\hline EWMA (ENRJ) & 1.023143 & 0.05356638 & 1.023143 & 0.05347541 \\
\hline EWMA (NAK) & 0.8038977 & 0.03178796 & 0.7917174 & 0.03203627 \\
\hline Normal (ENRJ) & 0.7429963 & 0.08183895 & 0.7308161 & 0.08153183 \\
\hline Normal (NAK) & 0.7551766 & 0.01371889 & 0.7308161 & 0.01399949 \\
\hline HS (ENRJ) & 0.9500609 & 0.02229024 & 0.9257004 & 0.0219003 \\
\hline HS (NAK) & 1.242387 & 0.009581244 & 1.205847 & 0.009917231 \\
\hline GARCH(1,1)(ENRJ) & 2.28989 & 0.07081975 & 2.216809 & 0.07078083 \\
\hline GARCH(1,1) (NAK) & 1.144945 & 0.02573922 & 1.084044 & 0.02595559 \\
\hline GARCH(2,2) (ENRJ) & 2.25335 & 0.07122537 & 2.180268 & 0.07119667 \\
\hline GARCH(2,2) (NAK) & 1.096224 & 0.02578427 & 1.010962 & 0.02595401 \\
\hline APARCH(1,1) (ENRJ) & - & - & - & - \\
\hline APARCH(1,1) (NAK) & 1.181486 & 0.02228844 & 1.096224 & 0.02245804 \\
\hline
\end{tabular}

Table 10. Backtest results for Historic Simulation with and without lpc for PVaR and EPS

\begin{tabular}{|l|c|c|}
\hline & Without lpc & With lpc \\
\hline HS PVaR's VR (ENRJ) & 1.162325 & 0.8416834 \\
\hline HS PVaR's VR (NAK) & 1.242387 & 1.205847 \\
\hline HS EPS's NS (ENRJ) & 0.9194093 & 0.9226193 \\
\hline HS EPS's NS (NAK) & 1.016545 & 1.026807 \\
\hline
\end{tabular}

Observe from Tables 9 and 10 that the behaviour of the proposed methodology is similar for the two stocks which is expected due to the generality of the proposed methodology.

\section{Conclusions}

In this work, we proposed the low price correction technique for improved forecasts of risk measures like Value at Risk and Expected Shortfall. The technique by definition is both simple and clear and its implementation is straightforward. EPS and PVaR estimations after the implementation of the low price correction, either remain unaffected or are improved in all examples considered. The proposed technique is widely applicable since it can be applied to any risk measure and any estimating method chosen by the investigator, while it does not require estimation of any additional parameters. It should also be noted that the estimates produced become admissible, in the sense that their values can be realized by the returns due to the fact that they are multiples of the minimum possible return. Consequently, unacceptable models become acceptable due to the fact that lpc performs best when models fail the most. In all cases the error measurements were significantly decreased. This consistency is what we believe is the greatest advantage our the proposed methodology. For future work we intend to explore the statistical significance of the 
International Journal of Mathematical, Engineering and Management Sciences

Vol. 4, No. 3, 542-566, 2019

https://dx.doi.org/10.33889/IJMEMS.2019.4.3-044

improvement observed via our analysis. The proposed technique is always applicable, but its superiority and effectiveness is evident in extreme economic scenarios and severe stock collapses.

Our methodology that pays attention not only to the asset return but also to the asset price, provides sufficient evidence that prices could contain important information which could, if taken under consideration, result in improved forecasts of risk estimation.

\section{Conflict of Interest}

The authors confirm that this article contents have no conflict of interest.

\section{Acknowledgements}

This work was completed as part of the research activities of the Laboratory of Statistics and Data Analysis of the University of the Aegean.

\section{References}

Acerbi, C., \& Tasche, D. (2002). Expected shortfall: a natural coherent alternative to value at risk. Economic Notes, 31(2), 379-388.

Artzner, P., Delbaen, F., Eber, J.M., \& Heath, D. (1999). Coherent measures of risk. Mathematical Finance, 9(3), 203-228.

Baillie, R.T., Bollerslev, T., \& Mikkelsen, H.O. (1996). Fractionally integrated generalized autoregressive conditional heteroskedasticity. Journal of Econometrics, 74(1), 3-30.

Belkhouja, M., \& Boutahary, M. (2011). Modeling volatility with time-varying FIGARCH models. Economic Modelling, 28(3), 1106-1116.

Black, F. (1976). Studies of stock price volatility changes, Proceedings of the 1976 Meetings of the American Statistical Association, 171-181.

Bollerslev, T. (1986). Generalized autoregressive conditional heteroskedasticity. Journal of Econometrics, 31(3), 307-327.

Bollerslev, T., \& Ghysels, E. (1996). Periodic autoregressive conditional heteroscedasticity. Journal of Business \& Economic Statistics, 14(2), 139-151.

Broda, S.A., \& Paolella, M.S. (2011). Expected shortfall for distributions in finance. In Statistical Tools for Finance and Insurance (pp. 57-99). Springer, Berlin, Heidelberg.

Campbell, S.D. (2007). A review of backtesting and backtesting procedures, The Journal of Risk, 9(2), 1-17

Clendenin, J.C. (1951). Quality versus price as factors influencing common stock price fluctuations. The Journal of Finance, 6(4), 398-405.

Cont, R. (2001). Empirical properties of asset returns: stylized facts and statistical issues, Quantitative Finance, 1(2), 223-236.

Christie, A.A. (1982). The stochastic behavior of common stock variances: Value, leverage and interest rate effects. Journal of Financial Economics, 10(4), 407-432.

Danielsson, J. (2011). Financial Risk Forecasting: The Theory and Practice of Forecasting Market Risk, with Implementation in R and Matlab (Wiley Finance Series). John Wiley \& Sons Incorporated. 
International Journal of Mathematical, Engineering and Management Sciences

Vol. 4, No. 3, 542-566, 2019

https://dx.doi.org/10.33889/IJMEMS.2019.4.3-044

Demirgüç-Kunt, A., \& Levine, R. (1996). Stock markets, corporate finance, and economic growth: an overview. The World Bank Economic Review, 10(2), 223-239.

Desai, H., \& Jain, P.C. (1997). Long-run common stock returns following stock splits and reverse splits. The Journal of Business, 70(3), 409-433.

Engle, R.F. (1982). Autoregressive conditional heteroscedasticity with estimates of the variance of United Kingdom inflation. Econometrica: Journal of the Econometric Society, 50(4), 987-1007.

Fritzemeier, L.H. (1936). Relative price fluctuations of industrial stocks in different price groups. The Journal of Business of the University of Chicago, 9(2), 133-154.

Gilbertson, R.A.C., Affleck-Graves, J.F., \& Money, A.H. (1982). Trading in low priced shares: An empirical investigation 1968-1979. Investment Analysts Journal, 11(19), 21-29.

Hwang, S., \& Lu, C. (2008). Is share price relevant?. https://papers.ssrn.com/sol3 /papers.cfm?abstract_id=1341790

Jana, M., Panda, G. \& Agrawal, N. (2018). An efficient portfolio with several objectives and varying parameters. International Journal of Mathematical, Engineering and Management Sciences, 3(4), 335350.

Lambert, P., \& Laurent, S. (2001). Modelling financial time series using GARCH-type models with a skewed Student distribution for the innovations (No. UCL-Université Catholique de Louvain).

Robinson, P.M. (1991). Testing for strong serial correlation and dynamic conditional heteroskedasticity in multiple regression. Journal of Econometrics, 47(1), 67-84.

Poon, S.H., \& Granger, C.W. (2003). Forecasting volatility in financial markets: A review. Journal of Economic Literature, 41(2), 478-539.

Siouris, G.J., \& Karagrigoriou, A. (2017). A low price correction for improved volatility estimation and forecasting. Risks, 5(3), 45.

Taylor, J.W. (2004). Volatility forecasting with smooth transition exponential smoothing. International Journal of Forecasting, 20(2), 273-286.

Waelkens, K., \& Ward, M. (1997). The low price effect on the Johannesburg Stock Exchange. Investment Analysis Journal, 26(45), 35-48.

Wang, L. \& Alexander, C.A. (2019). Big data analytics in healthcare systems, International Journal of Mathematical, Engineering and Management Sciences, 4(1), 17-26.

Zaremba, A., \& Żmudziński, R. (2014). The low price effect on the Polish market. e-Finanse, 10(1), 69-85. 